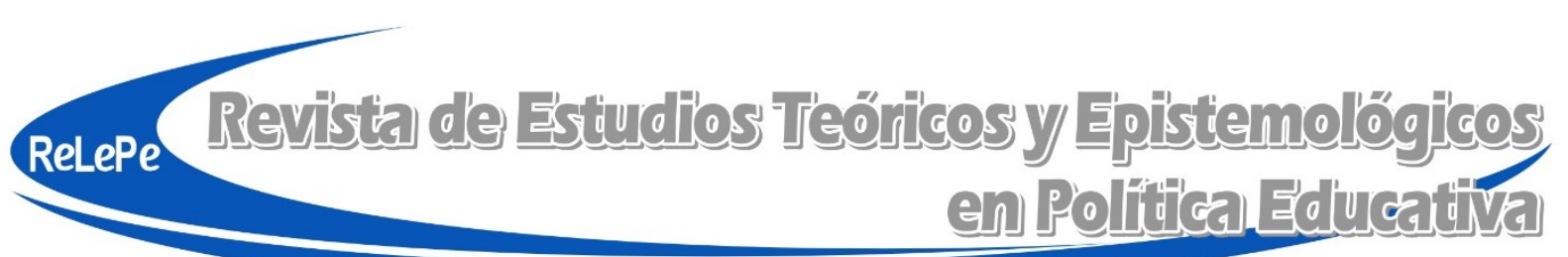

ISSN 2409-3696

DOI: $10.5212 /$ retepe.v.4.024

\title{
Apontamentos sobre epistemologia: algumas contribuições para a análise de políticas educativas
}

\author{
Katherine Gomez Plata \\ Universidade Estadual de Ponta Grossa \\ ktgomezplata@gmail.com \\ https://orcid.org/0000-0003-2992-164X \\ Simone de Fátima Flach \\ Universidade Estadual de Ponta Grossa \\ eflach@uol.com.br \\ https://orcid.org/0000-0002-9445-0111
}

Resumo: O artigo apresenta, a partir de pesquisa bibliográfica, o desenvolvimento da epistemologia, situa e contextualiza historicamente alguns fundamentos teóricos e metodológicos para a construção de conhecimento, destacando o método e suas divergências mais notáveis. Objetiva discutir a importância da epistemologia na educação, tendo em conta a produção do conhecimento com a finalidade da transformação do ser humano e suas implicações na natureza e na sociedade. Por fim, aponta como os estudos epistemológicos podem colaborar na compreensão e na análise de políticas educativas.

Palavras-chave: Epistemologia. Política educacional. Análise de políticas.

\section{Notes on epistemology: some contributions to the analysis of education policies}

Abstract: The paper presents, from bibliographic research, the development of epistemology, it situates and historically contextualizes some theoretical and methodological foundations for the construction of knowledge, highlighting the method and its most notable divergences. It aims to discuss the importance of epistemology in education, taking into account the production of knowledge for the purpose of transforming human beings and their implications for nature and society. Finally, it points out how epistemological studies can collaborate in the understanding and analysis of education policies.

Palavras-chave: Epistemology. Education policy. Policy analysis.

\section{Apuntes sobre epistemología: algunas contribuciones al análisis de políticas educativas}

Resumen: El artículo presenta, basado en la investigación bibliográfica, el desarrollo de la epistemología, sitúa y contextualiza históricamente algunos fundamentos teóricos y metodológicos para la construcción del conocimiento, destacando el método y sus divergencias más notables. El objetivo es discutir la importancia de la epistemología en la educación, teniendo en cuenta la producción del conocimiento con la finalidad de la transformación del ser humano y sus implicaciones para la naturaleza y sociedad. Finalmente, señala cómo los estudios epistemológicos pueden colaborar en la comprensión y en el análisis de políticas educativas.

Palabras clave: Epistemología. Política Educativa. Análisis de políticas. 
Apontamentos sobre epistemologia: algumas contribuições...

\section{Introdução}

Neste texto, pretendemos abordar as transições da sociedade em dado período histórico, de modo a evidenciarmos suas características essenciais e a forma como a organização do Estado ${ }^{1}$ pode influenciar/determinar na produção do conhecimento. A produção do conhecimento expressa, em cada momento histórico, a hegemonia de determinado grupo, a qual é endossada pelo Estado.

O desenvolvimento de novos métodos para produzir conhecimento ocorreu em concomitância ao desenvolvimento das sociedades. A expansão de territórios por meio de guerras e de invasões, o comércio entre povos e a interação social, resultado desse processo, colaborou para a transformação de como os sujeitos viam e percebiam o mundo. Esses fatos contribuíram para o surgimento e o desenvolvimento de novos métodos para gerar conhecimentos. Nesse sentido, Tonet (2013, p. 10) afirma que "[...] a justa compreensão da problemática do conhecimento implica que este seja tratado sempre em sua articulação íntima como conjunto do processo histórico e social, permitindo, assim, compreender a sua vinculação, mesmo que indireta, com determinados interesses sociais". Dessa maneira, pode-se ter uma melhor compreensão dos diversos métodos de construir o conhecimento, desenvolvidos ao longo da história.

O modo de produção capitalista, pautado em produção de mercadorias, em produtos detentores de valor, fez emergir a valorização da produção do conhecimento no âmbito das ciências exatas e naturais, visto serem estas reconhecidas como possibilidades concretas de resolução dos problemas humanos, já que seus produtos estariam comprometidos em suprir necessidades mais imediatas. Nesse contexto, as ciências humanas tiveram sua importância secundarizada e seus métodos foram desvalorizados.

No âmbito das Ciências Humanas em geral, e das Ciências da Educação em específico, há necessidade de consolidação de métodos que possam colaborar com a produção de conhecimentos comprometida com a qualidade da educação e com a transformação social. Nessa perspectiva, as pesquisas desenvolvidas nessa área precisam desvelar as contradições da realidade, de modo a colaborar com o questionamento das ações político-educacionais promovidas pelo Estado, visto que, no atual modo de produção, tais ações estão comprometidas com os interesses da classe que exerce o domínio e determina a direção da sociedade. É por isso que as Ciências Humanas representam sério risco ao atual modo de produção e organização social, pois, ao desvelar as contradições da realidade, evidenciam aquilo que não é percebido de maneira imediata e põe a nu as relações cobertas pelo manto da igualdade capitalista. Assim, a produção do conhecimento colabora para uma visão para além do capital, do capitalismo e de todas as suas sutilezas.

As pesquisas em Ciências Humanas e, em específico em Educação, podem ser entendidas como um ato verdadeiramente revolucionário, visto que colaboram para uma formação para além do capital. No entanto, a escolha de uma corrente filosófica ou método científico capaz de nortear as investigações e análises não é ato aleatório, mas emerge da vida material e do processo formativo do pesquisador. Em sua formação, o pesquisador conhece as diversas teorias e métodos desenvolvidos, analisa e compreende a realidade de cada época e, consequentemente, toma posição a respeito daquilo que pretende defender no momento histórico em que vive. Essa tomada de posição é determinante para a investigação e o conhecimento produzido a partir dela. Por isso, todo conhecimento é datado e precisa ser entendido como resultado do momento histórico em que foi produzido.

\footnotetext{
${ }^{1}$ Estado é aqui entendido na acepção gramsciana, formado pela sociedade civil + sociedade política, exercendo influência no modo de vida da sociedade (seja por coerção ou consenso).
} 
Tendo em vista a discussão sobre a importância da epistemologia em pesquisas no campo da política educacional, este artigo apresenta uma contextualização histórica sobre o desenvolvimento da epistemologia, propõe reflexão sobre sua relevância na educação e, por fim, indica como os estudos epistemológicos podem colaborar para a análise de políticas educacionais.

\section{Fundamentos teórico-epistemológicos do campo da educação}

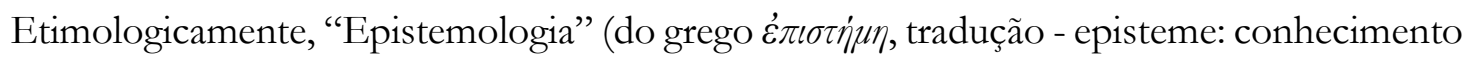

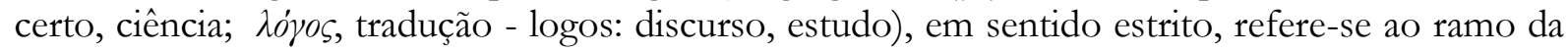
filosofia que se ocupa do conhecimento científico; é o estudo crítico dos princípios, das hipóteses e dos resultados das diversas ciências, com a finalidade de determinar seus fundamentos lógicos, seu valor e sua importância objetiva. Em uma acepção mais restrita, a epistemologia pode ser identificada com a filosofia da ciência.

A epistemologia tem suas raízes na filosofia da ciência, embora, nas últimas décadas, tenha obtido uma significativa autonomia com relação a esta, transformando-se em uma área relevante. Podemos dizer que o princípio fundamental da epistemologia é o estudo da realidade a partir da relação que se estabelece entre objeto e sujeito, tendo como pressuposto o método e a metodologia adotados pelo pesquisador.

Para Gamboa (2007, p. 27), a epistemologia "[...] é parte da filosofia que se ocupa especialmente do estudo crítico da ciência em seu detalhamento prático, isto é, da ciência como produto e como processo; nesse sentido, é um estudo fundamentalmente a posteriori". Para o autor, a epistemologia “[...] não é uma teoria geral do saber ou teoria do conhecimento". Na mesma esteira de pensamento, Japiassu (1992) define a epistemologia de forma geral como "[...] o estudo metódico e reflexivo do saber, de sua organização, de sua formação, de seu desenvolvimento, de seu funcionamento e de seus produtos intelectuais" (JAPIASSU, 1992, p. 16).

O delineamento do percurso histórico da epistemologia colabora para a compreensão das Ciências da Educação, seus métodos e seus fundamentos. Luzuriaga (1985) toma como referência os fatores políticos, filosóficos, religiosos, sociais etc., entendendo que a educação está submetida ao mesmo processo histórico que a cultura e a sociedade. Nesse contexto, alerta que a materialidade histórica desses aspectos e sua relação com os métodos hegemônicos precisam ser considerados.

Sendo a epistemologia considerada como teoria do conhecimento, a qual possibilita oferecer caráter de cientificidade ao conhecimento produzido, podemos inferir que uma determinada epistemologia colabora para o desenvolvimento do conhecimento científico. No que se referem ao campo político educacional, os estudos epistemológicos oferecem as condições necessárias para a análise de políticas educativas. Desse modo, pode-se produzir conhecimento científico sobre tais políticas.

Para melhor compreender os fundamentos epistemológicos que orientaram e orientam a organização e a análise da educação, e também sobre as políticas educativas, apresentamos as teorias epistemológicas que se fizeram/fazem presentes no campo educacional e, consequentemente, podem auxiliar na análise de políticas educacionais passadas e presentes, e ainda, indicar possibilidades futuras. 
Apontamentos sobre epistemologia: algumas contribuições...

\section{Teorias epistemológicas na Filosofia Greco- Medieval}

Na Grécia Antiga (1200 a. C. até o ano 146 a. C.), o povo helênico foi dividido em várias cidades-estados ${ }^{2}$ (polis). De maneira geral, nesses espaços, havia um estilo de vida semelhante, e os indivíduos compartilhavam uma série de elementos culturais que os identificavam: a língua grega, a religião (politeístas), e, por fim, valorizavam o diálogo. Para os gregos, o ser humano era, acima de tudo, um ser pensante, e, por isso, valorizavam a palavra, visto que esta estimulava e permitia expressar o pensamento. $\mathrm{Na}$ organização social, havia classes diferenciadas. De um lado, havia pessoas livres, formadas por cidadãos (Militares, Políticos, Judiciários, Sociais) e não cidadãos (Clerucos e Metecos); e, por outro, existiam sujeitos não livres, os escravos.

Luzuriaga (1985) divide a educação Grega em quatro períodos fundamentais: Educação heroica ou cavalheiresca; Educação cívica, representada por Atenas e Esparta; Educação humanista e Educação helenística. A Educação heroica ou cavalbeiresca, representada pelos poemas homéricos, era baseada essencialmente no conceito de honra e de valor, sendo sua maior expressão evidenciada na obra Ilíada, na qual se apresentam ações que demonstram as virtudes e os valores, bem como o conjunto de qualidades que distinguem um herói. A Educação cívica concentrou-se nas duas grandes polis da Grécia: Esparta e Atenas. Na educação Espartana, deixada inteiramente nas mãos do Estado, o ideal homérico é transformado em heroísmo, no amor à pátria, havendo substituição do guerreiro individual homérico ao ideal coletivo do estado, existindo uma educação inteiramente nas mãos do Estado. A educação do jovem guerreiro era evidenciada na arte da guerra, na educação física completa e nas artes musicais e na oratória. Na Educação Ateniense, há uma centralidade da educação cívica espiritual, na consciência cívica, no espírito democrático, na liberdade política, aspectos fundamentais da vida ateniense.

Segundo Luzuriaga (1985, p. 41): "No século V a sociedade e a cultura atenienses experimentam mudança ainda mais radical que a anterior; e origina-se a chamada educação nova". Nesse período, surgem os Sofistas, conhecidos como os primeiros educadores conscientes da história. Os sofistas empreenderam a atividade docente com o fim de transformar Atenas, pois os homens livres precisavam de uma educação mais intelectual, educação para a vida pública, a formação política e a capacidade de oratória. Dentre esses educadores, destacou-se Protágoras (485 a.C.- 411 a.C.), o filósofo que colocou o homem no centro do pensamento, com sua afirmação: "O homem é a medida de todas as coisas" ${ }^{3}$. Segundo ele, a verdade dependia da experiência pessoal, que qualquer afirmação sempre era relativa a um ponto de vista, a uma sociedade ou ao modo de pensar. No entanto, Sócrates (470 a.C. - 399 a.C.) discordava dos sofistas quanto ao diálogo para impor ideias e defendia a verdade absoluta e as verdades de valor universal, de modo que o diálogo deveria estimular o pensamento, por meio do método indutivo.

$\mathrm{Na}$ Grécia antiga, iniciaram as fundações de cultura superior, como a Academia de Platão, considerada um antecedente das universidades, em que os alunos e os mestres realizavam estudos superiores de caráter filosófico e político. Além disso, Platão, conhecido como fundador da teoria da educação, justificava a correlação entre o Estado e a Educação, em razão da reflexão pedagógica associada à política. Platão foi mestre de Aristóteles, sendo que este fundou o Liceu, escola de orientação empírica que seguia pressupostos do pensamento aristotélico. Segundo tais princípios, o sujeito acessa ao conhecimento pelos sentidos, e, desse modo, o conhecimento está vinculado ao mundo físico.

\footnotetext{
${ }^{2}$ A Grécia era dividida em diversos Estados, cidades-estados. As mais conhecidas são as antagônicas Esparta e Atenas, cada uma delas caracterizada por um tipo de educação.

${ }^{3}$ Formulação clássica de Protágoras no diálogo escrito por Platão, entre Teeteto e Sócrates.
} 
Por fim, o último período da Educação Grega, a Educação Helenística: "Perde intensidade da época clássica de Sócrates, Platão e Aristóteles. [...]. A educação passa a ser pública, também existe o ensino privado" (LUZURIAGA, 1985, p. 42). Marcou-se uma cultura cada vez mais científica caracterizando-se a aplicação de métodos e objetos de estudo, permitindo a evolução da ciência física. A filosofia e a histografia apresentaram-se amadurecidas, começou a consolidação de estudos na astronomia, na geometria e na matemática, como também na botânica, na zoologia, na gramática, dando vida a uma enciclopédia bastante complexa do saber.

É importante destacarmos que a pedagogia grega não pode ser considerada como ciência propriamente dita, mas seus aportes na teoria da educação são valiosos nos dias atuais. Nesse sentido, Luzuriaga destaca:

O importante dessa época é que deixa estabelecido, com sua enciclopédia, o programa de estudos que o mundo ocidental despois seguirá durante muitos séculos, com o trivium e o quadrivium; aquele compreendia gramática, retórica e filosofia ou dialética; este, aritmética, música, geometria e astronomia; quer dizer: a divisão em matérias humanísticas e realistas que perdurou no mundo. Ao falar da cultura helenística, a que chama "religião da cultura". (LUZURIAGA, 1985, p. 43).

Por fim, cabe destacarmos que a constituição da propriedade privada regulava a sociedade na Grécia, estabelecendo-se diferenças entre pessoas, constituindo o conceito do cidadão que prevalece em nossos dias: aquele que tem participação na política e na sociedade. Naquele contexto, o cidadão recebia educação que o preparava para tais fins; contudo, nem todos eram cidadãos, fato que impedia o livre acesso ao conhecimento e, consequentemente, à participação política.

A mudança na concepção do mundo fez mudanças na política e, mesmo assim, os grandes avanços alcançados pela ciência grega não continuaram em vigor quando Roma substituiu a Grécia (146 a. C.) como a grande potência do Mediterrâneo. Com isso, teve início a Filosofia Medieval, um período que se estendeu desde que a cosmovisão cristã foi imposta na esfera cultural grega e romana, até a crise da humanidade europeia no século XVI.

Ao contrário do que aconteceu com a filosofia grega, que centrou sua reflexão em torno da determinação do objeto, a filosofia medieval concentrou seu interesse em Deus. A filosofia helenística tinha dado uma orientação prática ao conhecimento, direcionando-o para a felicidade do homem - distinto da escolástica cujo desenvolvimento da consciência moral colocou a ética no ápice do conhecimento. A filosofia medieval estava dominada culturalmente pela religião, impedindo o avanço nas ciências e destruindo grande parte do conhecimento gerado na Grécia antiga, pois consideravam produto de filósofos pagãos. Por isso, a Idade Média pode ser considerada como a Idade das Trevas.

$\mathrm{Na}$ Antiga Grécia, havia forte influência politeísta, visto que se acreditava que os deuses influenciavam a vida dos sujeitos. Contrariando esse princípio, em razão da forte influência do cristianismo, na época Medieval, acreditava-se em um só Deus. Nesse período, caracterizado pela fé, surgiu uma associação entre filosofia e cristianismo ou, mais geralmente, entre filosofia e religião. Segundo esse entendimento, o único que existe por si só é Deus e que o mundo e os homens são 
o que são porque Deus nos dá o ser. Os dois filósofos mais destacados desse período foram: Agustín de Hipona ${ }^{4}$ e Tomás de Aquino ${ }^{5}$.

$\mathrm{Na}$ Idade Medieval, a Igreja teve uma função civilizatória (organização do conhecimento, formação do homem cristão). A educação foi um esforço para levar o homem à perfeição e, consequentemente à felicidade. No início, os sacerdotes eram os educadores, os quais, fundamentados nos escritos bíblicos, elaboravam doutrinas a respeito das verdades de fé do cristianismo. Nesse processo, originou-se a Patrística, filosofia Cristã da qual seu maior representante foi Santo Agostinho. A Patrística encontra-se na transição entre a filosofia da antiga Grécia e a era Cristã, sendo que Santo Agostinho fez uma ligação entre a filosofia de Platão e o pensamento cristão. O neoplatonismo permitia dar respostas razoáveis às questões intelectuais, baseadas na fé Cristã, pois, segundo ele: "O neoplatonismo era visto como uma doutrina que, com ligeiros retoques, parecia capaz de auxiliar a fé cristã a tomar consciência da própria estrutura interna e defender-se com argumentos racionais, elaborando-se como teologia" (SANTO AGOSTINHO, 1980, p. 10). Dessa forma, "Agostinho retorna à questão principal da Patrística, ou seja, ao problema das relações entre a razão e a fé, entre o que se sabe pela convicção interior e o que se demonstra racionalmente, entre a verdade revelada e a verdade lógica, entre a religiosidade cristã e a filosofia pagã” (SANTO AGOSTINHO, 1980, p. 17).

Segundo Santo Agostinho, o conhecimento é explicado pela teoria da iluminação, a consciência é iluminada por Deus. Esse pensador estabelece uma diferença entre o conhecimento sensível, aquele alcançado por médio do corpo, realizado pela alma, e o conhecimento racional, o conhecimento de verdades universais e necessárias, ideias, o mundo das ideias leva a consciência divina. "Assim, só haveria uma resposta possível: a aceitação de que alguma coisa transcende a alma individual e dá fundamento à verdade. Seria Deus” (SANTO AGOSTINHO, 1980, p. 20).

Enquanto o pensamento de Santo Agostinho defende uma subordinação da razão em relação da fé, surgiu um movimento filosófico, a Escolástica, que buscava uma harmonização entre a fé e a razão, linha defendida por Tomás de Aquino. Ao dar autonomia à razão para a obtenção de respostas, baseava-se na inovação do aristotelismo, porém sem negar à fé. Tomás de Aquino introduziu elementos da filosofia de Aristóteles ao pensamento escolástico. Defendia como princípio de que o fim do homem era "[...] o aperfeiçoamento de sua natureza, o que somente pode cumprir-se em Deus". Nesse sentido: “A finalidade última das ações humanas transcenderia, portanto, ao próprio homem, cuja vontade, mesmo que ele não o saiba, leva-o a dirigir-se ao ser supremo” (SÃO TOMÁS DE AQUINO, 1988, p. 14).

Para ele, compreender a natureza permite justificar que Deus existe e, a partir das relações que o homem estabelece com o mundo em que vive, ele consegue obter conhecimento. Nesse sentido, o conhecimento é gerado pela relação bicondicional da fé e da razão. "Por ser a nossa inteligência incapaz de apreender a essência divina em si mesma, eleva-se ao seu conhecimento a partir das coisas criadas. Nestas encontram-se diversas perfeições, porém a única raiz e origem de todas reside em Deus" (SÃO TOMÁS DE AQUINO, 1988, p. 121).

Embora o grande avanço na produção de conhecimento possa ser situado na Antiga Grécia, as conquistas feitas pelo Império Romano, permitiram a expansão da cultura e da religião para uma grande parte da Europa, consolidando os avanços feitos em prol da ciência por Platão e Aristóteles. A produção de conhecimento na época Greco-medieval teve um rompimento no momento que a

\footnotetext{
${ }^{4}$ Agustín de Hipona (354-430), universalmente conhecido como Santo Agostinho, foi educado na tradição helênica, na escola de retórica de Cartago. Entre suas obras mais conhecidas, estão as Confissões e a Cidade de Deus.

5 Tomás de Aquino (1225-1274), maior exponente da Escolástica, procurou elaborar uma síntese entre a educação cristã e a educação greco-romana.
} 
Igreja ganhou poder conjunto do Estado, estabelecendo as condições para seu desenvolvimento. No entanto, a necessidade de colocar a fé cristã acima da razão, tornou impossível o avanço dos métodos para produzir conhecimento.

Além disso, o modo de produção em ambas as épocas é similar e fundamentado no trabalho direto do homem com a natureza, seja trabalho de escravos, seja trabalho de servos. A propriedade privada era um meio para garantir direitos na sociedade, na produção de riquezas e nos benefícios econômicos. A esse respeito, Tonet (2013) comenta que:

Para além das diferenças, que certamente existem, os modos de produção escravista e feudal têm algumas características importantes em comum. Ambos são bastante estáticos. Suas estruturas sociais, de longa duração, parecem ter um caráter de imutabilidade e de naturalidade. Isto se deve, essencialmente, ao fato de que a forma de produzir a riqueza - terra e escravos ou terra e servos, respectivamente tem uma dinâmica interna muito pequena e uma limitação insuperável. (TONET, 2013, p. 18).

No entanto, a história mostrou que não há realidade insuperável. A profunda crise econômica derivada do sistema feudal e os privilégios da nobreza demonstraram a fragilidade para sua manutenção. Diante de uma burguesia que ameaçava chegar ao poder e das transformações que estariam por vir, a sociedade medieval sucumbiu e a produção do conhecimento sofreu profundas transformações.

\section{Teorias epistemológicas na Filosofia Moderna}

A característica essencial na transição do período medieval para o período moderno é o modo de produção. O desenvolvimento das forças produtivas para transformar a natureza e a consequente transição da economia feudal para a capitalista trouxe consigo grandes transformações para a sociedade. A necessidade de melhorar a produção de riquezas impulsionou $\mathrm{O}$ desenvolvimento científico, e vice versa. Nesse período, a autoridade da Igreja passou a ser questionada, houve um rompimento com os dogmas religiosos tidos como verdade absoluta, o que possibilitou o renascimento cultural e científico.

Durante um período tão longo quanto a Idade Média, surgiram alguns pensadores na Europa que, sem questionar os ensinamentos da Igreja, tentaram criticar alguns dos princípios da ciência aristotélica e procuraram outros meios para chegar ao conhecimento verdadeiro. A carência de um método rigoroso para produzir conhecimento influenciou a revolução científica que ocorreu durante o Renascimento. Nesse período, destaca-se o filosofo René Descartes ${ }^{6}$, que adotou a razão pura, que tinha por princípio o pensar com a finalidade de buscar respostas para as questões dos fenômenos físicos e naturais. Tais questões estavam expressas no Discurso do Método ${ }^{7}$, o qual promovia uma reflexão independente da fé e alcançou certa autonomia em relação ao pensamento até então em vigor. Contudo, a filosofia da Escolástica nunca deixou de estar presente no espírito de Descartes. "E eu tinha sempre um imenso desejo de aprender a distinguir o verdadeiro do falso, para ver claro em minhas ações, e caminhar com segurança nesta vida" (DESCARTES, 2001, p. 14).

\footnotetext{
${ }^{6}$ René Descartes $(1596$ - 1650), filósofo, físico e matemático francês. Um dos pensadores mais importantes e influentes da História do Pensamento Ocidental, chave na Revolução Científica.

${ }^{7}$ Discurso sobre o método, para bem conduzir a razão na busca da verdade dentro da ciência, é o principal trabalho escrito por René Descartes e um trabalho fundamental da filosofia ocidental com implicações para o desenvolvimento da filosofia e da ciência.
} 
Esse período pode ser relacionado com o grande desenvolvimento das ciências, visto que a pesquisa era constantemente praticada em quase todas as partes da Europa. A física então dominante era aquela pregada pela Escolástica, procedente de Aristóteles. Entretanto, o século XVII rompeu com essa imagem do mundo e com esses hábitos de pensamento para constituir uma física quantitativa, matemática, suscetível de inúmeras aplicações, na qual o mundo era apreendido como uma imensa máquina. Não obstante, a Igreja teve ainda participação nas políticas do Estado, penalizando filósofos e cientistas que ousavam ser contrários aos ensinamentos cristãos.

Um exemplo disso foi a sentença de morte recebida por Galileu Galilei ${ }^{8}$, que mesmo sabendo que contradizer a teoria geocêntrica poderia levá-lo à inquisição por heresia, divulgou os resultados obtidos por meio do método científico que comprovaria a teoria de Nicolau Copérnico?. Retraiu-se pouco antes de morrer, pelo qual recebeu sentença de prisão domiciliar até sua morte. Em razão desse fato, Descartes, com receio por represálias por parte da Igreja, publicou anonimamente o Discurso do Método, no qual definiria as bases para o método científico moderno.

No primeiro princípio da filosofia de Descartes, "Penso, logo existo", ele tinha a certeza da própria subjetividade, do próprio Eu, percebia o indivíduo como ser pensante sem a realidade externa limitada por Deus. A esse respeito, ele escreveu: “[...] reconheci que eu era uma substância, cuja única essência ou natureza é pensar, e que, para existir, não necessita de nenhum lugar nem depende de coisa alguma material” (DESCARTES, 2001, p. 38). Entretanto, segundo ele, “[...] em penso, logo existo nada há que me garanta que digo a verdade” (DESCARTES, 2001, p. 39). Para resolver tais impasses, ele propôs uns princípios para distinguir o verdadeiro e o falso para reformar seu pensamento, resultado de seus estudos em lógica, análise geométrica e em álgebra.

O primeiro era de nunca aceitar coisa alguma como verdadeira sem que a conhecesse evidentemente como tal; $\mathrm{O}$ segundo, dividir cada uma das dificuldades que examinasse em tantas parcelas quantas fosse possível e necessário para melhor resolvê-las; $O$ terceiro, conduzir por ordem meus pensamentos, começando pelos objetos mais simples e mais fáceis de conhecer; o último, fazer em tudo enumerações tão completas, e revisões tão gerais, que eu tivesse certeza de nada omitir. (DESCARTES, 2001, p. 23).

Com os avanços ocorridos no período renascentista, enormes progressos ocorreram, não apenas no campo científico, mas também nos campos social, político e cultural. O pensamento de filósofos e cientistas contribuiu para a adoção progressiva da observação, do experimento e da indução, para a rejeição da autoridade e, consequentemente, para a libertação da ciência das amarras instituídas no período anterior. Esses fatos colaboraram para que a Europa Ocidental estivesse preparada para avançar na construção de um projeto de reforma social, intelectual e moral. $\mathrm{O}$ máximo expoente desse período foi Immanuel Kant ${ }^{10}$, o qual escreveu sua obra principal A Crítica da Razão Pura ${ }^{11}$. Nessa obra, Kant fez uma reflexão acerca da relação entre sujeito e objeto, e, ainda, perseguiu o entendimento sobre os alcances e os limites do conhecimento, buscando conhecer os seus fundamentos.

Kant partiu da consciência, das representações fenomenais do Eu, fosse do mundo externo ou interno. Tratou, desde o início, da estética e da lógica transcendental, cujo método baseava-se na sensibilidade e no entendimento do sujeito sobre os conceitos. Ele conseguiu estabelecer um

\footnotetext{
${ }^{8}$ Galileu Galilei (1564 -1642), físico, matemático, astrônomo e filósofo.

${ }_{9}^{9}$ Nicolás Copérnico (1473- 1543), matemático, astrônomo, jurista, físico, clérigo católico, governador, diplomata e economista.

${ }^{10}$ Immanuel Kant (1724- 1804), filósofo, professor, representante da crítica e precursor do idealismo alemão.

${ }^{11}$ A crítica da rąãa pura é a principal obra do filósofo prussiano Immanuel Kant. Teve sua primeira edição em 1781.
} 
método que incorporava a razão e a sensibilidade para acessar a um conhecimento com rigidez. Ao fazer essa conjunção de racionalismo e empirismo, ele criticou as correntes filosóficas que enfocavam o objeto como fonte de conhecimento e colocou o sujeito como a fonte que construía o conhecimento.

No século XVIII, século da filosofia por excelência, Kant deu status de ciência para a metafisica, com uma base teórica própria, método e objeto, pois a fé não mais explicava a realidade, evidenciando a necessidade de uma ruptura dogmática para produzir conhecimento. O filósofo fez um chamado em sua resposta $O$ que é Esclarecimento?, representando o movimento iluminista dessa época.

A saída do homem de sua menoridade, da qual ele próprio é culpado. A menoridade é a incapacidade de fazer uso de seu entendimento sem a direção de outro indivíduo. O homem é o próprio culpado dessa menoridade se a causa dela não se encontra na falta de decisão e coragem de servir-se de si mesmo sem a direção de outrem. Sapere aude! Tem coragem de fazer uso de teu próprio entendimento, tal é o lema do esclarecimento. (KANT, 1985, p. 100).

No âmbito desse processo revolucionário de construção do conhecimento, houve, conjuntamente à Revolução Industrial, um abalo nas estruturas sociais, culminando com a mudança do modo de produção. Influenciada pelas mudanças tecnológicas, socioeconômicas e culturais, a economia deixou de ser baseada na agricultura e no artesanato para depender da indústria, afetando todas as estruturas da sociedade. Nesse contexto, surgiu uma vertente do idealismo filosófico, o idealismo absoluto, na qual o filósofo Georg Wilhelm Friedrich Hegel ${ }^{12}$ se tornou seu grande precursor. Hegel considerava, a partir do enfoque fenomenológico, a subjetividade dos sujeitos.

$\mathrm{Na}$ obra Fenomenologia do Espírito ${ }^{13}$, Hegel tratou do desenvolvimento, da formação da consciência desde sua origem (Experiência da consciência). A partir da crítica a Kant, que considerava a consciência algo natural, em Hegel o conhecimento era colocado em movimento. Sendo um grande estudioso da filosofia grega, fez uso de princípios dialéticos de Aristóteles no seu pensamento, tais como: o movimento, a relação ato-potência e o movimento - contradição. Segundo ele, tudo existe porque há movimento e pela contradição se define o real. A dialética de Hegel considerava a realidade como contraditória e a partir de suas contradições é possível chegar ao status de ciência, filosofia em movimento, saber em ação.

[...] o conhecimento filosófico unifica também esses dois movimentos particulares. A gênese interna ou o devir da substância, é inseparavelmente, passagem no exterior ou no existir, ser para outro, e inversamente, o devir do existir é o reconquistar a si mesmo na essência. Dessa sorte, movimento é o processo duplicado e o devir do todo, de modo que cada momento põe ao mesmo tempo o outro e, portanto, cada um tem em si ambos os momentos como dois aspectos. Por meio desse movimento eles constituem juntos o todo, na medida em que a si mesmos se dissolvem e se fazem momentos do todo. (HEGEL, 1974, p. 30).

Experimentando durante sua vida o boom da revolução industrial e sua consolidação, Hegel fez uma crítica ao sistema capitalista. Hegel introduziu a concepção dialética da história, segundo a qual a história se mantinha em constante desenvolvimento e era constituída por formas dialéticas que constituíam a totalidade. Ao mesmo tempo, para Hegel, o homem era o sujeito consciente que

\footnotetext{
12 Georg Wilhelm Friedrich Hegel (1770-1831), filósofo alemão. Principal idealista do século XIX alemão.

13 A Fenomenologia do Espírito é uma das obras mais importantes do filósofo alemão Georg Wilhelm Friedrich Hegel, publicada em 1807.
} 
fazia a história e, por conseguinte, a história desse sujeito visava atingir o Espírito Absoluto. Segundo ele, o capitalismo (a sociedade capitalista) era o fim da história, o fim do espírito absoluto. Após a sua morte, em 1831, terminou um período de grandes avanços na ciência, a consolidação de metodologias para produzir conhecimento, a transformação de uma sociedade. É importante destacarmos que, no pensamento de Hegel, se assentaram as bases para que nascesse uma nova interpretação do mundo. Essa nova interpretação de mundo considerava a realidade imediata, que esta tinha aparências que precisavam ser desveladas para que a essência fosse conhecida e compreendida.

\section{Teorias epistemológicas na Filosofia Contemporânea: contribuições de Hegel e Marx}

Tendo sido profundamente marcada pela Revolução Industrial, a filosofia contemporânea estende-se do final do século XVIII até os dias de hoje, influenciando o pensamento e o modo de vida dos indivíduos. Os séculos XVIII e XIX foram marcados por profundas alterações culturais, filosóficas, econômicas e sociais. Uma dessas transformações foi a Revolução Industrial, a qual produziu uma revolução tecnológica que modificou totalmente a antiga forma manual de produção, substituindo o homem por máquinas e a fabricação individual pela produção em massa. Esse fato histórico pode ser indicado como determinante para a expansão do capitalismo em todo o mundo, evidenciando contradições insolúveis no processo de ampliação do capital. Fundamentada na exploração do trabalho humano, a lógica capitalista mostrou toda a sua força para, não apenas produzir mercadorias, mas determinar como os indivíduos vivem e sobrevivem em uma sociedade dividida.

Entretanto, quando o capitalismo ainda era uma possibilidade histórica que lutava pelo seu fortalecimento, a produção do conhecimento também estava marcada pelo pensamento de filósofos da época. Dentre tais filósofos, destaca-se Georg Wilhem Friedrich Hegel (1770-1831), o qual pode ser considerado um marco para o desenvolvimento da filosofia contemporânea e a forma de ver e entender o mundo e a ciência. O pensamento hegeliano é expresso em diferentes obras, as quais mostram seu desenvolvimento e o compromisso em entender o mundo a partir das ideias ou da elaboração de conceitos. Para Hegel, importava compreender o objeto pelo conceito, ou seja, o conhecimento dependeria não da realidade material, mas da capacidade de racionalizá-la, pois "[...] a ciência pode organizar-se somente por intermédio da vida própria do conceito" (HEGEL, 1974, p. 35). Nesse sentido, "[...] no estudo da ciência, tudo consiste em tomar sobre si o esforço trabalhoso do conceito" (HEGEL, 1974, p. 35), evidenciando um esforço dialético em tornar a realidade uma abstração, sendo esta o próprio conceito.

De forma subliminar, podemos inferir que o pensamento hegeliano, baseado no idealismo, compreende a realidade a partir do pensamento, ou do espírito, ou, ainda, que o objeto é o conceito racionalizado. Assim, a filosofia hegeliana é baseada na dialética como um método filosófico que busca definir e resolver as contradições do pensamento e da realidade histórica por meio da racionalização. A partir da crítica da economia política do sistema capitalista e dos aspectos que fazem parte da produção capitalista, Karl $\mathrm{Marx}^{14}$ e seu fiel companheiro intelectual e de luta política, Friedrich Engels, levaram o idealismo dialético hegeliano à realidade material, transformando-a no materialismo dialético, cujo método foi desenvolvido por Marx em sua obra principal: O Capital ${ }^{5}$.

Todavia, a elaboração d'O Capital foi precedida de um conjunto de reflexões e de debates com pensadores que o antecederam ou que, com ele, teceram discussões profícuas para apontar

\footnotetext{
14 Karl Heinrich Marx (1818- 1883), de origem judia, considerado filósofo, economista, sociólogo, periodista, intelectual e militante comunista.

15 O Capital é um conjunto de livros, sendo o primeiro de 1867.
} 
que não bastava interpretar a realidade, mas transformá-la. Marx e Engels apontaram uma perspectiva revolucionária para o conhecimento, pois a interpretação deveria ser o guia para a transformação da realidade dos homens, não sendo possível esta ocorrer apenas pelo pensamento, visto que "[...] a discussão sobre a realidade ou a irrealidade do pensamento - isolado da práxis é puramente escolástica" (MARX; ENGELS, 2001, p. 100). Por isso, o conhecimento não pode ficar circunscrito apenas na interpretação, mas deve ir à realidade e transformá-la. Entretanto, para isso, necessita partir da própria realidade. Em suas palavras:

Ao contrário da filosofia alemã, que desce do céu para a terra, aqui é a terra que se sobe ao céu. Em outras palavras, não partimos do que os homens dizem, imaginam e representam, tampouco do que eles são nas palavras, no pensamento, na imaginação e na representação dos outros, para depois se chegar aos homens de carne e osso; mas partimos dos homens em sua atividade real [...]. (MARX; ENGELS, 2001, p. 19).

No materialismo histórico dialético, não existem fenômenos isolados, pois são os homens, de forma coletiva que, a partir de sua "[...] produção material e suas relações materiais, transformam, com a realidade que lhes é própria, seu pensamento e também os produtos do seu pensamento" (MARX; ENGELS, 2001, p. 19-20). Nessa perspectiva, o materialismo histórico e dialético, elaborado por Marx e Engels, deu um salto qualitativo em relação à filosofia até então existente, pois, segundo eles, "[...] não é a consciência que determina a vida, mas sim a vida que determina a consciência” (MARX; ENGELS, 2001, p. 20).

Sendo a realidade o ponto de partida, a consciência expressa um movimento dialético e se materializa como reflexo da vida. A esse respeito, Marx esclarece que:

O último método é manifestamente o método cientificamente exato. O concreto é concreto, porque é a síntese de muitas determinações, isto é, unidade do diverso. Por isso, o concreto aparece no pensamento como o processo da síntese, como resultado, não como ponto de partida, embora seja o verdadeiro ponto de partida e, portanto, o ponto de partida também da intuição e da representação. (MARX, 2008, p. 258).

A dialética marxista ensina um modo de abordar os fenômenos da natureza e da sociedade; é o único método científico de estudo e de conhecimento do mundo que serve como guia para a revolução humana. As exigências mais importantes do método dialético marxista são: a verificação pela prática das verdades obtidas e a consideração de todas as mudanças relacionadas ontologicamente ao ser humano.

Ao contrário de outros filósofos, Marx não expôs o método marxista em um documento, não elaborou um passo a passo do que deve ser feito, mas indicou a prática em diversos escritos. Por isso, para melhor entender tal perspectiva, é preciso se debruçar sobre seus escritos e aliar seus ensinamentos à vida prática, à atividade política e revolucionária, pois, como ele e Engels ensinaram ao tecerem críticas à Feuerbach, "[...] é na práxis que o homem precisa provar a verdade, isto é, a realidade e a força, a terrenalidade do seu pensamento" (MARX; ENGELS, 2001, p. 100).

As contribuições do materialismo histórico e dialético espraiam-se por diversos campos, tais como o direito, a economia, a sociologia e a história (dentre outros), impulsionando muitos pesquisadores a utilizarem o método e seu pensamento para entender e estudar a realidade, a fim de transformá-la. Ainda, o marxismo também influenciou a ideologia política dos partidos socialistas, bem como os movimentos revolucionários em todo o mundo. Além disso, o Materialismo histórico e dialético evidencia as contradições do modo de produção capitalista, de modo a despertar da consciência de classe dos trabalhadores, para que juntos possam lutar pela 
instauração de uma sociedade justa, que tenha como fundamento a emancipação humana. A esse respeito são esclarecedoras as palavras de Lukács:

\begin{abstract}
Somente com a entrada do proletariado em cena o conhecimento da realidade social encontra seu cumprimento: com o ponto de vista de classe do proletariado emerge uma perspectiva a partir da qual a totalidade da sociedade tornasse visível. O que surgiu com o materialismo histórico foi, ao mesmo tempo, a teoria "das condições da libertação do proletariado" e a teoria da realidade do processo total do desenvolvimento histórico, precisamente porque, para o proletariado, isto é uma necessidade vital, uma questão de vida ou de morte - a questão de alcançar a visão mais perfeitamente clara da sua situação de classe. (LUKÁCS apud TONET, 2013, p. 67).
\end{abstract}

As contribuições do marxismo para o processo de tomada de consciência da realidade pelos trabalhadores são incomensuráveis, visto que, somente a partir da compreensão da materialidade concreta, de suas contradições, é possível interferir para que a transformação seja possível. Nesse sentido, o pensamento marxista, na qualidade de teoria epistemológica que orienta e fundamenta a construção do conhecimento científico, é profícuo, visto que não se contenta com verdades acabadas, mas entende a realidade como processo de construção histórica, a qual só ocorre por meio da ação coletiva.

\title{
A epistemologia e a análise de políticas educativas
}

O desenvolvimento do conhecimento científico esteve, ao longo da história humana, atrelado a determinadas formas de entender a realidade vivida. As condições, as possibilidades, a legitimidade e os limites do conhecimento científico não são neutros, visto que sempre estiveram ligados ao pensamento de determinada época, o qual é representado por diferentes pensadores, os quais demonstram vinculação com determinado modo de ver e entender o mundo. Não é sem propósito que diferentes filósofos se dedicaram em esclarecer pressupostos para o desenvolvimento da ciência.

Nesse sentido, Saviani $(2017$, p. 2) esclarece que a "[...] epistemologia tem como objeto o estudo das condições de possibilidade, legitimidade, valor e limites do conhecimento científico". Isso quer dizer que, sem epistemologia, não há como produzir conhecimento científico. Ainda esclarece que, em razão disso, "[...]a epistemologia das políticas educacionais sinalizaria para o estudo das condições de possibilidade, legitimidade, valor e limites do conhecimento científico que se pode produzir sobre as políticas educacionais" (SAVIANI, 2017, p. 2). O conhecimento, portanto, precisa estar alicerçado em determinada epistemologia, a qual lhe dá caráter de cientificidade. Por isso, para a produção de conhecimento ser reconhecida como produção científica, precisa ter sólida teoria que o conduz.

Em se tratando de política educativa, além de sólida teoria que embase a análise, é preciso considerar o momento histórico, os interesses implícitos ou explícitos que a orientam e o grau de efetividade para sua materialização. Além disso, o seu reconhecimento como status científico precisa passar pela validação de profissionais (cientistas consagrados) que reconhecem o caráter científico do conhecimento produzido.

Uma das principais questões buscadas pelo conhecimento científico é a compreensão da realidade material, baseada em critérios de verdade manifestados em determinados períodos históricos, os quais procuram analisar a prática vivida, dar-lhes significado e indicar possibilidades para sua permanência ou transformação. Por isso, o enfoque epistemológico utilizado na análise de políticas educacionais é fundamental para dar validade ao conhecimento produzido, 
demonstrando o rigor do pesquisador com os dados analisados, seus efeitos na prática política e na vida dos indivíduos envolvidos.

Nas investigações sobre políticas educacionais, o enfoque epistemológico adotado pelo pesquisador demonstra seu compromisso com determinados critérios de verdade. Conforme abordado nesse texto, as contribuições epistemológicas de vários pesquisadores contribuíram para que a realidade fosse analisada e compreendida em sua totalidade. No entanto, todas as teorias epistemológicas estiveram vinculadas ao modo de produção e de vida de cada época, e, em certa medida, colaboram para a análise das políticas educativas atuais.

As teorias epistemológicas greco-medievais, desenvolvidas sob os auspícios da exploração do trabalho humano, seja pela escravidão ou servidão, fundamentaram um construto teórico baseado nas crenças e na fé. Tais pensamentos, com critérios de verdade aceitos na época, foram utilizados para justificar a organização social, política, cultural e econômica, ora servindo para o avanço, ora para a paralização do desenvolvimento científico. Se, no primeiro período, o conhecimento produzido possibilitou desenvolvimento nas diversas áreas, demonstrando a preocupação científica com a explicação do universo, o segundo período demonstrou a força da fé para barrar a produção científica, condenando aqueles que, de alguma forma, questionaram o status quo fundamentado na religiosidade. A análise da educação daquela época exigiu a compreensão do construto epistemológico que fundamentou as práticas daquele momento histórico e que, atualmente, se mostram presentes em algumas propostas políticas em curso no Brasil.

As teorias epistemológicas moderna e contemporânea, da mesma forma, desenvolveramse vinculadas à realidade material. Do modo de produção feudal para o modo de produção capitalista, o salto em termos de conhecimento científico é incomensurável. A partir do questionamento dos conhecimentos defendidos pela Igreja, houve significativo avanço científico, o qual possibilitou o desenvolvimento tecnológico e a criação de novos critérios de verdade para explicar a realidade.

As contribuições epistemológicas das diversas teorias podem (e devem) sustentar a análise de políticas educacionais. No entanto, a análise precisa considerar as relações das previsões teóricas com a prática política e educacional, pois, conforme já alertou Gramsci (2004),

[...] um movimento filosófico só merece este nome na medida em que busca desenvolver uma cultura especializada para restritos grupos de intelectuais ou, ao contrário, merece-o na medida em que, no trabalho de elaboração de um pensamento superior ao senso comum e cientificamente coerente, jamais se esquece de permanecer em contato com os "simples" e, melhor dizendo, encontra neste contato a fonte dos problemas que devem ser estudados e resolvidos? (GRAMSCI, 2004, p. 100).

A análise de políticas educacionais, portanto, além de ter uma sólida teoria epistemológica que a sustente, precisa relacionar-se à realidade material, oferecer interpretações significativas que colaborem para que os problemas educacionais possam ser compreendidos e resolvidos. Não basta estudá-los, é preciso oferecer alternativas possíveis para a prática política, pois somente por meio "[...] deste contato é que uma filosofia se torna 'histórica', depura-se dos elementos intelectualistas de natureza individual e se transforma em 'vida"' (GRAMSCI, 2004, p. 100).

\section{Considerações finais}

Desde a antiguidade até os dias atuais, o homem tem se preocupado em produzir conhecimentos que lhe permitam desenvolver melhor suas atividades sociais e culturais. A 
princípio, a produção de conhecimento visava elevar o espírito, na justificação dos fenômenos naturais e na resolução de problemas relativos à existência humana. Atualmente, em razão das necessidades do capitalismo, há novos interesses para a produção de conhecimento.

O conhecimento "relevante" produzido consolidou-se no campo das ciências naturais, visto que assegura o desenvolvimento de pesquisas que sejam úteis no processo de industrialização e de produção. O Estado, não sendo neutro, acompanha as necessidades do capitalismo, propondo políticas educativas que respondam às exigências do mercado. Tais políticas têm se vinculado ao processo de desumanização do ser humano, visto que, ao subordinar-se aos pressupostos do modo de produção capitalista, distancia o homem do próprio produto de seu trabalho. Por isso, pesquisar sobre a relação entre o papel do Estado, a formulação de políticas para a educação e o capitalismo tem sido objeto de estudo no campo das Ciências Humanas. As teorias epistemológicas contribuem para tais pesquisas, oferecendo um construto teórico para a análise e as proposições de alternativas viáveis para dado momento histórico.

Entretanto, a relevância da epistemologia na produção de conhecimento não deve se preocupar somente com o ponto de vista do método, das técnicas ou da abordagem. O fim último da pesquisa precisa refletir sobre as razões para que a realidade material seja da forma como é e propor alternativas de transformação, pois, como Marx já alertou, "[...] os filósofos só interpretaram o mundo de diferentes maneiras; do que se trata é transformá-lo” (MARX, 2001, p. 103).

A produção do conhecimento ao longo da história contribuiu para o progresso permitindo o desenvolvimento nas dimensões sociais e culturais. Entretanto, também se transformou em instrumento do capitalismo, pois seus interlocutores definem, segundo suas necessidades, a relevância e o objeto de estudo nas pesquisas. A esse respeito, Gamboa (2007) afirma que:

O conhecimento tem sentido quando revela as alienações, as opressões e as misérias da atual fase de desenvolvimento da humanidade, questiona criticamente os determinantes econômicos sociais e históricos e dá potencialidade à ação transformadora. O conhecimento crítico do mundo e da sociedade e a compreensão de sua dinâmica transformadora propiciam ações (práxis) emancipadoras. A práxis elevada à categoria epistemológica fundamental se transforma em critério de verdade e de validez científica. A práxis significa reflexão e ação sobre uma realidade, buscando sua transformação. Transformação orientada para a consecução de maiores níveis de liberdade do indivíduo e da humanidade em seu devir histórico (interesse crítico emancipador). (GAMBOA, 2007, p. 113).

Por fim, considera-se que a epistemologia tem em sua essência uma reflexão crítica sobre a realidade e contribui para a análise dos critérios pelos quais o conhecimento é justificado, além de considerar as circunstâncias históricas que levam à sua obtenção. Portanto, o papel fundamental que desempenha na produção de conhecimento, seja nas Ciências Naturais, seja nas Humanas, deve ser o mesmo: Transformar a realidade! O processo de análise de políticas educativas não pode se distanciar dessa afirmação.

\section{Referências}

DESCARTES, R. Discurso do método. São Paulo: Martins Fontes, 2001.

GAMBOA, S. S. Pesquisa em educação Chapecó: Argos, 2007.

GRAMSCI, A. Cadernos do Cárcere. v. 1. 3. ed. Rio de Janeiro: Civilização Brasileira, 2004. 
HEGEL, G. W. F. Fenomenologia do espírito. São Paulo: Abril Cultural. 1974. (Coleção Os pensadores).

JAPIASSU, H. Introdução ao pensamento epistemológico. Rio de Janeiro: Francisco Alves, 1992.

KANT, I. Resposta à pergunta: o que é o esclarecimento. In: KANT, I. Textos Seletos. Tradução Raimundo Vier. 2. ed. Petrópolis: Vozes, 1985. p. 100-117.

LUZURIAGA, L. História da educação e da pedagogia. 16. ed. São Paulo: Companhia Editora Nacional, 1985.

MARX, K. Teses sobre Feuerbach. In: MARX, K.; ENGELS, F. A ideologia alemã. São Paulo: Martins Fontes, 2001. p. 99-103.

MARX, K. O método da economia política. In: MARX, K. Contribuição à Crítica da Economia Política. Tradução e introdução de Florestan Fernandes. 2. ed. São Paulo: Expressão Popular, 2008. p. 237-268.

MARX, K.; ENGELS, F. A ideologia alemã. São Paulo: Martins Fontes, 2001.

SANTO AgOSTINHO. Santo Agostinho. Confissões; De Magistro. 2. ed. São Paulo: Abril Cultural, 1980. (Coleção Os Pensadores).

SÃO TOMÁS DE AQUINO. São Tomás De Aquino; Dante Alighieri. Seleção de textos. São Paulo: Nova Cultural, 1988. (Coleção Os Pensadores).

SAVIANI, D. Epistemologias da política educacional: algumas precisões conceituais. ReLePe Revista de Estudios Teóricos y Epistemológicos en Política Educativa, v. 2, p. 1-5, 2017. DOI: https://doi.org/10.5212/retepe.v.2.002

TONET, I. Método científico: uma abordagem ontológica. São Paulo: Instituto Lukács, 2013. p. 65-128.

Recebido em: 20/12/2020

Versão corrigida recebida em: 13/02/2020

Aceito em: $15 / 02 / 2020$

Publicado online: 19/02/2020

\section{Katherine Gomez Plata}

Licenciada em Matemáticas pela Universidade do Atlantico. Mestre em Educação pela Universidade Autônoma do Caribe. (UAC). Doutoranda em Educação na Universidade Estadual de Ponta Grossa (UEPG). Membro do Grupo de Pesquisa Capital, Trabalho, Estado e Educação.

\section{Simone de Fátima Flach}

Doutora em Educação pela Universidade Federal de São Carlos (UFSCar). Professora da Universidade estadual de Ponta Grossa - Programa de Pós-graduação em Educação (Mestrado e Doutorado). Co-diretora da Relepe - red de Estudios Teóricos y Epistemológicos en Política Educativa. Membro do Grupo de Pesquisa Capital, Trabalho, Estado e Educação. 